Rabaska

Revue d'ethnologie de l'Amérique française

\title{
LACROIX, BENOÎT. La Foi de ma mère. La Religion de mon père. Montréal, Bellarmin, 2002, 498 p. ISBN 2-89007-934-1
}

\section{Jean Simard}

Volume 3, 2005

URI : https://id.erudit.org/iderudit/201728ar

DOI : https://doi.org/10.7202/201728ar

Aller au sommaire du numéro

Éditeur(s)

Société québécoise d'ethnologie

ISSN

1703-7433 (imprimé)

1916-7350 (numérique)

Découvrir la revue

Citer ce compte rendu

Simard, J. (2005). Compte rendu de [LACROIX, BENOÎT. La Foi de ma mère. La Religion de mon père. Montréal, Bellarmin, 2002, 498 p. ISBN 2-89007-934-1].

Rabaska, 3, 154-156. https://doi.org/10.7202/201728ar

Ce document est protégé par la loi sur le droit d'auteur. L'utilisation des services d’Érudit (y compris la reproduction) est assujettie à sa politique d'utilisation que vous pouvez consulter en ligne.

https://apropos.erudit.org/fr/usagers/politique-dutilisation/
Cet article est diffusé et préservé par Érudit.

Érudit est un consortium interuniversitaire sans but lucratif composé de l’Université de Montréal, l’Université Laval et l’Université du Québec à Montréal. Il a pour mission la promotion et la valorisation de la recherche. https://www.erudit.org/fr/ 
LaCRoIX, Benoir. La Foi de ma mère. La Religion de mon père. Montréal, Bellarmin, 2002, 498 p. ISBN 2-89007-934-1.

Le livre n'est pas tout à fait nouveau. Il réunit le premier chapitre d'un premier ouvrage, La Religion de mon père, avec les quinze d'un deuxième, La Foi de ma mère, sans les illustrations ni les annexes. Le premier avait paru en 1985, le second en 1999. Dans le nouvel avant-propos, Benoît Lacroix insiste pour dire que son approche est celle du praticien de la culture populaire et de l'historien, pas celle de l'idéologue préoccupé par les frontières entre le profane et le sacré : « Aujourd'hui octogénaire, j'interroge encore les souvenirs d'un passé familial rempli de richesses et d'inédits. "

Le fils de Rose-Anna Blais et de Caïus Lacroix y peint une grande fresque de ce que fut le sentiment religieux vécu et partagé par l'immense majorité des Canadiens français de la fin du XIX' ${ }^{\mathrm{e}}$ siècle jusque dans les années 1960. Nous devrions même dire que la fresque est peinte à trois : l'auteur lui-même, né en 1915, qui a observé spontanément les siens à Saint-Michel de Bellechasse quand il était jeune, puis plus méthodiquement à la manière d'un ethnologue quand il descendait de Montréal visiter ses parents avec son habit de dominicain, mais aussi sa mère et son père, des « habitants des Hauts de Bellechasse », nés respectivement en 1882 et 1883 et dont la parole colorée est généreusement mise à contribution. 
L'auteur-mémorialiste reconstruit avec intelligence et sensibilité la vision que ses parents se faisaient de la terre et du ciel, vision résultant d'une traduction à l'échelle très humaine du plan divin où le code de discipline diocésaine réglait le rythme des saisons, des travaux et des jours sans laisser de répit. Comme disait sa mère : «le Bon Dieu, c'est le Bon Dieu. Il faut être propre pour le rencontrer. Tu te laves bien avant de t'endimancher. C'est la même chose avant d'aller communier, tu vas à confesse $»$. Et ainsi de suite dans les seize chapitres partagés en quatre parties qui traitent de l'héritage, du temps, de l'espace et des personnes sacrées. L'héritage, fait de soumission sans résignation (1760-1840) et de perception d'une autorité irréfutable (18401900), est comparé à celui qu'a reçu l'Occident européen à la fin du Moyen Âge. Mais ici, « le clergé était trop près du peuple pour ne pas comprendre son besoin de libération », ce qui expliquerait l'origine largement cléricale de la Révolution tranquille. Maintenant le temps. Il y a le temps du salut, celui de Noël, de Pâques, le temps du péché, du Sanctoral, puis le temps de la vie quotidienne où le ciel touche facilement à la terre de Bellechasse : « Ma mère soulignera au besoin qu'elle a travaillé " toute la sainte journée ". Et lui, papa, continuera à proclamer que labourer en mai, comme bûcher du bois en hiver, "ça fait des sacrées bonnes journées " ». L'espace est à l'échelle cosmique quand le curé parle du ciel, du purgatoire et de l'enfer, mais il est aussi sacré aux niveaux de la paroisse et de la maison. Au retour d'un pèlerinage à Sainte-Anne-de-Beaupré à bord du Champion, se souvient Benoît Lacroix, « nous regardons les Laurentides s'éloigner peu à peu de nous. L'île d'Orléans contournée, à mesure que nous enfilons les vagues, le clocher de Saint-Michel semble venir à notre rencontre pour nous accueillir. Nous avons l'impression, sinon la certitude, que nous habitons un pays sacré, le plus sacré qui soit ». Les personnes sacrées ne sont pas qu'au ciel. Il y a celles aussi qui s'y destinent, surtout le pape à Rome mais encore toutes les autres qui portent la robe : l'évêque de Québec, le curé, les frères et les sœurs de Saint-Michel. Cinq cents pages d'écriture lumineuse sur les trois siècles et demi qui ont fait le Québec dont nous sommes aujourd'hui les héritiers.

Que garderons-nous de l'héritage se demande l'auteur? Après une période qu'il qualifie de « mérovingienne », l'Église purifiée du Québec cache-t-elle assez de vitalité pour s'imposer au peuple dispersé ? Le lien historique entre le caractère catholique du Canada français et l'évolution politique des Québécois oblige-t-il l'avenir ? Et comment les Québécois feront-ils la paix avec leur passé religieux sans perdre l'acquis de leurs parents? Qu'elle soit « opium du peuple » ou « sel de la terre », la religion héritée des Québécois, écrit-il, « visera désormais la libération des consciences en faveur d'un engagement vis-à-vis de la vie, de la paix, de la non-violence et du bonheur des 
peuples ». Benoît Lacroix, maintenant nonagénaire, demeure encore l'éveilleur de conscience qu'il a toujours été.

JEAN SIMARD

Société québécoise d'ethnologie, Québec 